\title{
The Effects of Mindfulness-Based Personality Program on Middle School Students
}

\section{중학생 대상 마음챙김 기반 인성프로그램의 효과}

\author{
Seon Il Park ${ }^{1}$
}

박선일1

${ }^{1}$ Professor, Departmen of Nursing, Kwangju Women's University, Korea, psi2161@kwu.ac.kr

\begin{abstract}
The purpose of this study was to develop and apply the personality program using mindfulness-based meditation for middle-school students. A personality program using mindfulnessbased meditation was developed and adopted after review of the related study literature. The sample size consisted of 42 students. Personality Program was conducted once a week for 45 minutes for 4 sessions in total. Data collection was conducted prior to the start of the program, and a post-mortem survey was conducted in the 5th week. Each variable was measured using the corresponding research tool. Collected data were quantitatively analyzed by using SPSS 20.0 program, and were used for its site-compatibility and efficacy. The results of this study were as followings First, it was proved that the developed program in this study has considerable reliability in contents and purpose appropriateness. Second, the findings indicated that this program could improve students' self-esteem, self-understanding, self-disclosure according to the result of the analysis on the lessons through data collections from students. After the mindfulness-based Personality Program, scores of self-esteem, self-understanding, self-disclosure increased significantly. The results suggested that the Personality Program can expand into a mindfulness-based program of personality education to positively improve self-esteem, self-understanding and selfdisclosure.
\end{abstract}

Keywords: Middle School Students, Mindfulness, Personality Program, Self-understanding, SelfDisclosure, Self-esteem

요약: 이 연구의 목적은 중학생을 대상으로 마음챙김 기반 인성교육프로그램을 개발하여 적용 하는 데 있다. 이러한 목적을 달성하기 위하여 문헌 연구를 통해 마음챙김 기반 중학생 대상 인성교육프로그램 틀을 도출하고 전문가로부터 타당성을 검증받았다. 연구 대상자는 42 명의 학생이다. 주 1 회 45시간 4회기로 인성프로그램을 실시하였고 자료수집은 프로그램 시작 전에 사전 조사하였으며, 5 주 차에 사후 조사를 실시하였다. 각 변수의 측정은 해당 연구 도구를 이 용하여 측정하였다. 수집된 자료는 SPSS 20.0 프로그램을 이용하여 양적분석을 하였다. 자료수 집을 통해 적합성 및 효과성을 검증하였다. 이러한 연구에 따른 결과는 다음과 같다. 첫째, 마 음챙김 기반 중학생 인성교육프로그램 적용 내용 및 목표를 타당성 있게 개발하였다. 둘째, 학 생들의 자료수집의 통하여 본 프로그램이 학생들의 자아존중감, 자기이해, 자기개방을 향상시 킬 수 있음을 확인하였다. 마음챙김 기반 인성프로그램 후 자아존중감, 자기이해, 자기개방에 서 모두 통계적으로 모두 증가하였다. 추후 이러한 결과를 바탕으로 청소년 시기 중학생의 자 아존중감과 자기이해 및 자기 개방에 긍정적인 향상을 도모할 수 있는 인성교육프로그램으로

Received: March 22, 2021; 1st Review Result: May 07, 2021; 2nd Review Result: June 18, 2021 Accepted: July 31, 2021 
확장시키고자 한다.

핵심어: 중학생, 마음챙김, 인성프로그램, 자기이해, 자기개방, 자아존중감

\section{1. 서론}

우리나라의 청소년들은 다른 국가와 비교하여 지적역량은 상위권으로 매우 우수하나 타인에 대한 배려와 사회적 상호작용 역량이 최하위권으로 인성역량이 가장 부족한 수준 으로 나타났으며 청소년 핵심역량에 관한 지수에 대한 조사에서 학업성취 수준과 사회적 감성과 인성 지수의 수준의 불균형이 다른 국가와 비교하여 상당한 차이가 있다고 보고 하였다[1].

또한 한국교육개발원(KEDI)에서 전국 초, 중, 고 40,000 명을 대상으로 학교별 인성검사 를 실시한 결과 중학교의 인성 수준이 가장 낮게 나타났다[2]. 이러한 사회적 현상을 개 선하고자 2015년 인성교육 진흥법이 제정되어 인성교육 진흥법 제 2 조에서는 인성교육의 정의를 자신의 내면을 바르고 건전하게 가꾸고 타인·공동체·자연과 더불어 살아가는데 필 요한 인간다운 성품과 역량을 기르는 것을 목적으로 하는 교육을 의미한다로 명시되어 있다.

이에 교육부는 인성교육을 위한 국가적 지원이 종합적이고 일관된 방향으로 추진되도 록 인성교육 5 개년 종합계획을 세우고 있다. 인성교육 강화 방안과 인성교육 강화 기본 계획을 기반으로 2015 초·중등 개정 교육과정에 따라 중학교 교육과정의 목적은 학생의 학습과 일상생활의 기본 능력과 바른 인성 및 민주 시민의 자질을 함양하는 데 중점을 두고 자주적인 사람, 창의적인 사람, 교양 있는 사람, 더불어 사는 사람이라는 인간상을 기반으로 자신과 타인에 대한 이해에 초점을 두고 교육목표를 설정하고 있다.

중학생 시기에 접어든 청소년들은 신체적으로 급격한 변화가 일어나면서 인지와 정서 적으로 자기에 대한 의문을 갖게 되고, 자신에 대하여 고민하는데 이 시기를 부정적으로 경험하게 되면 자신의 가치에 대해 자신감이 저하되고 혼란스러워하게 된다[3][4]. 이러한 시기의 청소년들에게 자신에 대한 자기 개념과 정서적 및 심리적 안정과 만족감에 자기 의 가치와 특성에 대한 총체적인 신념인 자아존중감(self-esteem)은 중요한 역할을 한다[3] [5].

자아존중감은 스스로의 가치, 능력 및 중요성을 평가하는 것으로[6][7], 긍정적 만족감, 행복감 및 생활 만족에 대한 자신감과 적극성의 증가는 정서적, 심리적인 부분에 영향을 줄 수 있음으로 자신에 대해 존중하고 희망적인 미래를 생각 할 수 있게 한다[8][9]. 청소 년 시기에 자아존중감의 긍정적인 형성은 앞으로 사회에 나가 다양한 상황에 직면하게 되면 자신이 주체가 되어 긍정적인 사고로 여러 문제를 해결할 수 있을 것이다[9]. 이에 청소년들은 자신에 대하여 올바르게 바라보고 이해하는 것이 필요하다.

자기 이해는 자기의 신체적, 정서적, 사회적 상태와 대인관계, 가치관 등 자신에 대하 여 탐색하는 과정을 통하여 자신을 있는 그대로 이해하고 자신에 대하여 이해하고 수용 할 수 있을 때 타인을 이해하고 수용하며 신뢰하게 되면 자신을 타인에게 개방하는 자기 개방이 형성되어 자신의 생각과 감정을 상대방 등에게 표현하게 된다. 이러한 자기이해 와 자기개방은 자신에 대하여 긍정적 이해하고 수용하는 태도에 매우 주요한 영향을 줄 수 있으며 청소년 시기에 필요한 자신의 역할을 충실히 수행할 수 있도록 도울 것으로 보인다[9]. 
따라서 심리적 과도기에 있는 청소년이 자신의 잠재능력을 개발하고 성장할 기회를 제 공하여[10] 자신과 타인을 이해하는 역량을 갖추기 위해 적극적으로 사고하고 참여하는 것을 포함하여 공동체의 범위를 향상시킬 수 있도록 해야 한다[11]. 이에 정서적 불안정 성, 자아 혼란감을 극복하고 진정한 나라고 하는 새로운 자아를 확립하며 자아존중감, 자 기이해 및 자기개방에 대하여 긍정적인 에너지로 전환될 수 있도록 돕는 기회를 제공하 고자 마음챙김 기반 인성교육프로그램을 시행하고자 한다.

마음챙김은 정서적, 감각적으로 현재의 일어나는 것에 여러 자극에 대한 알아차림이다 [11]. 여러 문헌을 통하여 마음챙김을 활용한 프로그램들이 우울과 불안, 스트레스 등에 효과를 보이는 연구들이 이루어지고 있으며 마음챙김을 명상을 기반으로 자아존중감, 자 기개방, 자기이해에 대한 효과에 관하여 연구를 수행한 선행연구들이 있었으나[12-15] 마 음챙김을 활용하여 중학생의 정서적, 심리적 안정 등을 위한 마음훈련 및 자아존중감, 자 기개방, 자기이해에 긍정적인 영향을 제공하는 학습내용으로 구성된 인성교육프로그램의 효과에 대한 연구는 미비한 실정이다.

따라서 마음챙김을 기반으로 한 중학생 대상 인성프로그램을 개발하여 이를 적용하고 자아존중감과 자기이해 및 자기 개방에 영향을 미치는 효과를 알아보고 이에 마음챙김 기반 인성교육프로그램이 중학생의 정서적, 심리적 안정과 자아존중감에 긍정적인 향상 을 도모할 수 있는 인성교육프로그램으로 확장시키고자 한다.

\section{2. 연구방법}

\section{1 연구 설계}

본 연구는 마음챙김 기반 인성교육프로그램을 청소년 시기인 중학생에게 4 주간 적용하 여 자아존중감, 자기이해 및 자기개방에 미치는 효과를 확인하기 단일군 전후 유사실험 연구이다.

\section{2 연구 대상}

본 연구 대상자는 $\mathrm{J}$ 도에 위치한 중학교에 재학 중인 학생으로 연구의 대상자 수는 $\mathrm{G}$ Power 3.1.2 프로그램을 이용하여 산출하였다. 유의수준 0.05 , 효과 크기 0.8 , 검정력 0.8 을 기준으로 하였을 때 대상자 수는 30 명이었으나, 본 연구의 목적을 이해하고 연구 참여에 동의한 자로 연구에 참여한 45 명 중 모두 참여한 42 명을 대상으로 본 연구를 진행하였다

\section{3 연구 도구}

\subsection{1 자아존중감}

자아존중감 측정 도구는 [16] 의 자아존중감 척도 중 사회적 자아존중감에 해당하는 8 문항을 사용하였다. 매우 그렇다에서 전혀 그렇지 않다로 5점 척도이며 점수가 높을수록 자아존중감이 높은 것으로 본 연구에서의 Cronbach's $\alpha=.87$ 이었다.

\subsection{2 자기이해}

자기이해 측정 도구는 [17] 의 한 자기의식 척도 중 자기이해 하위척도 5 문항을 사용하 였으며 매우 그렇다에서 전혀 그렇지 않다로 5 점 척도이며 점수가 높을수록 자기이해의 
정도가 높음을 의미하며 본 연구에서의 Cronbach's $\alpha=.86$ 이었다.

\subsection{3 자기개방}

자기개방 측정 도구는 [18] 의 자기 성장 집단상담의 효과의 하위요인인 자기개방 수준 을 측정하기 위해 번안하여 사용한 6개 문항을 사용하였으며 매우 그렇다에서 전혀 그렇 지 않다로 5 점 척도이며 점수가 높을수록 자기개방의 정도가 높음을 의미하며 본 연구에 서의 Cronbach's $\alpha=.79$ 이었다.

\section{4 자료수집}

자료수집은 마음챙김 기반 중학생 대상 인성교육프로그램 시작 전 사전 조사, 시작 후 5 주 차에 사후 조사를 시행하였다. 각 측정 도구에 따른 설문지는 연구자가 직접 자료를 수집하였다.

\section{5 연구의 윤리적 측면}

연구 대상자의 윤리적 측면을 고려하기 위하여 먼저 해당 중학교 소속 교육지원청의 협조로 프로그램 지원 중등학교를 대상으로 무작위로 모집하여 추출하였으며, 프로그램 에 신청과 연 구참여에 동의한 연구 대상 중학교 기관장의 협조 승인과 진로 부장의 동 의를 받아 프로그램 시행할 수 있었다. 연구의 윤리적 측면을 강조하기 위하여 연구 대 상자에게 설문의 취지와 익명성, 비밀보장과 프로그램 진행 중 원하지 않으면 언제든지 중단 가능하다는 설명을 하였고 연구 참여 동의서에 서면 동의한 연구 대상자만 설문조 사를 실시하였다.

마음챙김 기반 중학생 대상 인성교육프로그램은 수행 전 전문가의 자문을 받고 최종 프로그램의 내용을 완료하여 연구 대상자에게 본 프로그램을 시행하였다. 연구 종료 후 프로그램을 신청한 1 개의 중학교에 대하여 4 회기에 걸친 프로그램을 수행하였다.

\section{6 연구 진행 절차}

\subsection{1 연구 사전 승인}

본 프로그램은 4단계로 구성된 마음챙김 기반 중학생 대상 인성교육프로그램으로 건강 한 자아존중감 형성과 인생의 다음 단계로 진입하기 위한 적응과 선 경험의 기회를 제공 하기 위한 목적으로 연구를 수행하기 전 연구 사전 승인을 위하여 $\mathrm{J}$ 도의 1 개 군의 교육 지원청의 센터장에게 연구의 목적을 설명하고 연구 계획서를 제출하였다.

마음챙김 기반 중학생 대상 인성교육프로그램을 진행하기 위하여 해당 교육청 소속 중 학교로 프로그램 참여에 대한 공문을 발송하였다. 프로그램 참여에 대한 신청서를 제출 한 중학교 중 1 개교를 무작위 선정하여 본 연구를 시행하였다.

코로나 19로 인하여 본 프로그램 실시 장소는 연구 참여자 간의 프로그램 시행에 필요 한 $2 \mathrm{~m}$ 의 공간의 확보가 가능한 중앙 도서관으로 하였으며, 해당 중학교의 기관장과 진로 부장과 직접 면담하여 연구의 목적을 설명하였고 설문조사에 대한 허락을 받았다.

\subsection{2 연구 준비}

본 프로그램을 수행하기 전 연구자들은 각 프로그램 주차 수행에 필요한 학습 교안을 
작성하고 필요한 마음블럭 등 학습교구를 준비하였다.

\subsection{3 프로그램 전 처지}

본 프로그램을 수행하기 전 연구자는 프로그램 실험 전 1 개교의 중학생 5 인을 대상으 로 2회기에 걸친 마음챙김을 기반 중학생 인성교육프로그램 per test를 실시하고 프로그램 내용 등을 일부 수정하였다. 프로그램 내용은 최종 전문 자문가에 의하여 자문 후 프로 그램을 확정하고, 프로그램에서 활용하는 마음블럭은 연구자에 의해 개발되어 본 프로그 램의 주요 학습교구로 활용하였다. 프로그램에서 주요 활용되는 마음블럭 및 마지막 회 차에 실시하는 감정 향수 적용법에 대하여 학습자에게 제공하는 학습 방법의 일관성을 유지하고자 연구자 외 연구보조자 1 인과 마음블럭 활용 방법과 감정 향수에 수행 방법에 대하여 학습 교안을 작성하고, 시범과 발표를 시행하여 프로그램 내용을 충실히 습득하 도록 하였다.

\subsection{4 프로그램 전 시행 및 사후 조사}

마음챙김 기반 인성교육프로그램은 연구 대상자에게 프로그램의 목적과 목표에 대하여 설명하는 것을 시작으로 1 단계 '나(자신의 이해)',2단계 '너(관계능력)', 3 단계 '우리(공동체 역량)',4단계 ‘꿈(진로 설계)’을 주제로 4단계의 프로그램으로 구성되었다. 단계별 4회기를 부여하여 프로그램을 수행하고자 학습안을 구성하였다. 본 연구는 4단계의 마음챙김 기 반 중학생 대상 인성교육프로그램의 1 단계인 '나(자신의 이해)'를 시행하였으며, 추후 2 , 3,4 단계로의 확산을 추진하고자 한다.

본 연구에서 시행한 1 단계 나(자신의 이해)의 목표는 자신을 잘 이해하고 사랑하기'를 목표로 자신에 대한 긍정적 존중감을 형성하고자 학습구성안을 작성하고 목적과 목표를 설정하였으며 회기별 세부 활동 매뉴얼로 만들어 회차별 내용을 구성하고 4회차로 교과 외 시간으로 정해진 시간에 프로그램을 수행하였다<Table 1>. 4회기 프로그램 종료 후 5 주 차 사후 조사를 하였으며, 사전 조사와 동일한 방법으로 연구자가 설문지를 통하여 직접 측정하였다.

[표 1] 마음챙김 기반 인성교육프로그램 1단계

[Table 1] Mindfulness-based Personality Program Step 1 'Me(Understand Oneself)'

\begin{tabular}{|c|l|c|}
\hline 1회기 : 오리엔테이션 및 자기소개 \\
\hline 목표 & $\begin{array}{l}\text { 프로그램의 목표에 대해 이해하고 기대감를 한다 } \\
\text { 지금까지의 모습을 돌아보고, 새로운 나로 성장하겠다는 의지를 } \\
\text { 갖는다. }\end{array}$ & $\begin{array}{c}1 \text { 회기 } \\
\text { (45분) }\end{array}$ \\
\hline 준비물 & $\begin{array}{l}- \text { 티라이트, 초, 촛대, 테이블, 테이블보, 필기구(색연필, 사인펜, 매직, 볼펜 등) } \\
- \text { 감정 카드, 명찰, A4용지, 마음블럭 교구 } \\
- \text { 음악(잔잔한 음악) }\end{array}$ \\
\hline 단계 & 진행 절차 \\
\hline
\end{tabular}




\begin{tabular}{|c|c|c|}
\hline $\begin{array}{l}\text { 도입 } \\
\text { (10분) }\end{array}$ & \multicolumn{2}{|c|}{$\begin{array}{l}\text { (1) 진행자와 보조진행자 소개 } \\
\text { (2) 오리엔테이션 진행 } \\
\text { - 프로그램은 } 4 \text { 개의 영역으로 구성 } \\
\text { - 나, 너, 우리를 알아가는 영역으로 구성 } \\
\text { - Me은 나는 어떤 사람인지, 나는 나를 어떻게 생각하고 있는지, 나를 소중하게 대하는 방법에 } \\
\text { 대해 알아가는 것 } \\
\text { - Another는 '너'와의 관계, 특히 친구 관계와 협동에 대해 알아가는 활동 } \\
\text {-Us, Mate는 '우리'가 평화롭게 함께 살아가는데 필요한 덕목을 키우는 활동 } \\
\text { (3) 테이블보를 씌운 테이블 위의 감정 카드 선정하기 }\end{array}$} \\
\hline $\begin{array}{l}\text { 이완 } \\
\text { (5분) }\end{array}$ & \multicolumn{2}{|l|}{$\begin{array}{l}\text { \# 몸과 마음의 이완(5분) } \\
\text { 이완과 편안함을 주는 명상 선택(정좌 명상) }\end{array}$} \\
\hline $\begin{array}{l}\text { 마음블럭 } \\
\text { 표현하기 } \\
\text { (25분) }\end{array}$ & \multicolumn{2}{|c|}{$\begin{array}{l}\text { (1) 자신의 상징 선정하기 } \\
\text { (2) 자신을 상징하는 상징물(표식이나 글, 모양 등)에 대해 생각해 보고 마음블럭으로 표현하고 } \\
\text { 발표 }\end{array}$} \\
\hline $\begin{array}{l}\text { 정리 } \\
(5 \text { 분 })\end{array}$ & \multicolumn{2}{|l|}{$\begin{array}{l}\text { (1) 마무리 소감 나누기 } \\
\text { (2) 티라이트 마무리 감정 카드 확인하기 }\end{array}$} \\
\hline \multicolumn{3}{|c|}{ 2회기 : 나의 뿌리를 찾아서 } \\
\hline 목표 & $\begin{array}{l}\text { ‘나’라는 인물이 만들어지는 데 영향을 미친 주변 어른들에 대해 } \\
\text { 생각해본다. }\end{array}$ & $\begin{array}{l}1 \text { 회기 } \\
\text { ( } 45 \text { 분) }\end{array}$ \\
\hline 준비물 & \multicolumn{2}{|l|}{$\begin{array}{l}\text { - 감정 카드, 8절 도화지, 필기구(색연필, 사인펜, 매직, 볼펜 등) } \\
\text { - 마음블럭 교구 - 음악(잔잔한 음악) }\end{array}$} \\
\hline 단계 & \multicolumn{2}{|l|}{ 진행 절차 } \\
\hline $\begin{array}{l}\text { 도입 } \\
\text { (5분) }\end{array}$ & \multicolumn{2}{|l|}{$\begin{array}{l}\text { (1) 시작의 촛불을 켜고 감정 카드 선정하기 } \\
\text { - 지난 회기 설명 - 이번 회기 소개 }\end{array}$} \\
\hline $\begin{array}{l}\text { 이완 } \\
(5 \text { 분) }\end{array}$ & \multicolumn{2}{|l|}{$\begin{array}{l}\text { \# 몸과 마음의 이완(5분) } \\
\text { 이완과 편안함을 주는 명상 선택(걷기 명상) }\end{array}$} \\
\hline $\begin{array}{l}\text { 마음블럭 } \\
\text { 표현하기 } \\
\quad(35 \text { 분) }\end{array}$ & \multicolumn{2}{|c|}{$\begin{array}{l}\text { (1) 나를 만든 사람들에 대해 마음블럭으로 표현 } \\
\text { (2) 활동 진행(소그룹 진행): 도화지에 학생들 자신만의 나무를 그리고 마음블럭을 활용하여 } \\
\text { 뿌리와 열매로 표현 } \\
\text { (3) 그룹 토의발표 실시 }\end{array}$} \\
\hline $\begin{array}{l}\text { 정리하기 } \\
\text { (5분) }\end{array}$ & \multicolumn{2}{|l|}{$\begin{array}{l}\text { (1) 회기 마무리 소감 나누기 } \\
\text { (2) 티라이트 마무리 감정 카드 확인하기 }\end{array}$} \\
\hline \multicolumn{3}{|c|}{ 3회기 : 장점 인터뷰 } \\
\hline 목표 & $\begin{array}{l}\text { 나의 긍정적인 특성과 부정적인 특성을 찾아본다. } \\
\text { 타인의 피드백을 통해 나의 긍정적인 특성을 강화한다. }\end{array}$ & $\begin{array}{l}3 \text { 회기 } \\
\text { (45분) }\end{array}$ \\
\hline 준비물 & \multicolumn{2}{|l|}{$\begin{array}{l}\text { - 감정 카드, 마음블럭 교구 } \\
\text { - 음악(잔잔한 음악) }\end{array}$} \\
\hline 단계 & \multicolumn{2}{|l|}{ 진행절차 } \\
\hline
\end{tabular}




\begin{tabular}{|c|c|c|}
\hline $\begin{array}{l}\text { 도입 } \\
\text { (5분) }\end{array}$ & \multicolumn{2}{|l|}{$\begin{array}{l}\text { (1) 초와 티라이트 감정카드 선정하기 } \\
\text { (2) 지난 회기에 진행한 내용에 대해 간단히 정리 }\end{array}$} \\
\hline $\begin{array}{l}\text { 이완 } \\
\text { (5분) }\end{array}$ & \multicolumn{2}{|l|}{$\begin{array}{l}\text { \# 몸과 마음의 이완(5분) } \\
\text { 이완과 편안함을 주는 명상 선택(걷기 명상) }\end{array}$} \\
\hline $\begin{array}{l}\text { 장점 나무 } \\
\text { 그리기 } \\
\text { (25분) }\end{array}$ & \multicolumn{2}{|l|}{$\begin{array}{l}\text { (1) 마음블럭으로 마이크를 만들어 자신의 장점 설명 } \\
\text { (2) 마음블럭으로 마이크를 만들어 친구의 장점 설명 }\end{array}$} \\
\hline $\begin{array}{l}\text { 정리하기 } \\
\text { (5분) }\end{array}$ & \multicolumn{2}{|l|}{$\begin{array}{l}\text { (1) 회기 마무리 소감 나누기 } \\
\text { (2) 티라이트 마무리 감정 카드 확인하기 }\end{array}$} \\
\hline \multicolumn{3}{|c|}{ 4회기 : ‘나’ 보충 활동: 감정 향수 만들기 } \\
\hline 목표 & $\begin{array}{l}\text { 아로마 오일을 이용하여 드러나지 않은 감정을 표현해 본다. } \\
\text { 감정적 혼란감을 수용하고, 감정적 균형을 찾도록 한다 }\end{array}$ & $\begin{array}{l}\text { 4회기 } \\
\text { (45분) }\end{array}$ \\
\hline 준비물 & \multicolumn{2}{|l|}{$\begin{array}{l}\text { - 아로마에센셜 오일 } \\
\text { - 향수병( } 5 \mathrm{ml} \text { 롤온 향수병) } \\
\text { - 마음블럭 교구 }\end{array}$} \\
\hline 단계 & \multicolumn{2}{|l|}{ 진행 절차 } \\
\hline $\begin{array}{l}\text { 도입 } \\
\text { (5분) }\end{array}$ & \multicolumn{2}{|l|}{$\begin{array}{l}\text { (1) 초와 티라이트 감정 카드 선정하기 } \\
\text { (2) 지난 회기에 진행한 내용에 대해 간단히 정리 }\end{array}$} \\
\hline $\begin{array}{l}\text { 이완 } \\
\text { (5분) }\end{array}$ & \multicolumn{2}{|l|}{$\begin{array}{l}\text { \# 몸과 마음의 이완(5분) } \\
\text { 이완과 편안함을 주는 명상 선택 }\end{array}$} \\
\hline $\begin{array}{l}\text { 감정 향수 } \\
\text { 만들기 } \\
\text { (30분) }\end{array}$ & \multicolumn{2}{|c|}{$\begin{array}{l}\text { (1) 감정 향수 만들기: } 6 \text { 종 감정 오일 이용 시 } 6 \text { 가지 오일 모두 향을 맡고, 나에게 끌리는 } \\
\text { 순서대로 왼쪽에서 오른쪽으로 나열하고 향수 제작 } \\
\text { (2) 마음블럭으로 꽃 만들어 향수 올리기 } \\
\text { 바디 스캔 하듯이 향기 명상 }\end{array}$} \\
\hline $\begin{array}{l}\text { 정리하기 } \\
\text { (5분) }\end{array}$ & \multicolumn{2}{|c|}{$\begin{array}{l}\text { (1) 회기 마무리 소감 나누기 } \\
\text { (2) 티라이트 마무리 감정 카드 확인하기 }\end{array}$} \\
\hline
\end{tabular}

\section{3. 연구 방법}

\section{1 연구 대상자의 일반적 특성}

연구 대상자의 일반적 특성으로 남학생 17 명(40.5\%), 여학생 23명 $(59.5 \%)$ 이며 1 학년 25 명(59.5\%), 2학년 9명(21.4\%), 3학년 8명(19.1\%)이었다. 평소 여가 시간에 하는 것은 게임을 하기 14명(33.3\%), 텔레비전이나 youtube 보기 9명(21.4\%), 인터넷 검색하기 8명(19.9\%), 운 동하기 6명(14.3\%), 음악 듣기 5명(11.9\%)의 순으로 나타났다<Table 2>.

\section{[표 2] 연구 대상자의 일반저 특성}

[Table 2] General Characteristics of Study Participants 


\begin{tabular}{|c|c|c|}
\hline Variables & Category & $\mathrm{n}(\%)$ \\
\hline \multirow{2}{*}{ Gender } & Male student & $17(40.5)$ \\
\hline & Female student & $23(59.5)$ \\
\hline \multirow{3}{*}{ Grade } & 1 & $25(59.5)$ \\
\hline & 2 & $9(21.4)$ \\
\hline & 3 & $8(19.1)$ \\
\hline \multirow{2}{*}{ Religion } & Yes & $9(21.4)$ \\
\hline & No & $33(78.6)$ \\
\hline \multirow{5}{*}{ What do you like doing for fun? } & Sports & $6(14.3)$ \\
\hline & Listening to music & $5(11.9)$ \\
\hline & Watch TV or y-tube & $9(21.4)$ \\
\hline & Internet & $8(19.0)$ \\
\hline & Playing Games & $14(33.3)$ \\
\hline
\end{tabular}

\section{2 마음챙김 기반 중학생 인성교육프로그램‘나(자신의 이해)' 사전 사후 효과 검정}

본 연구에서 시행한 마음챙김 기반 중학생 대상 인성교육프로그램인 1 단계‘나(자신의 이해)' 시행 전과 시행 후 효과에 관한 결과는 다음과 같다<Table 3>.

마음챙김 기반 인성교육프로그램 1단계 '나(자신의 이해)' 시행 전 자아존중감 3.26점, 시행 후 자아존중감 4.43점 $(\mathrm{t}=-8.847, \mathrm{p}<.001)$, 시행 전 자기이해 3.39점, 시행 후 자기이해 4.71점이었으며 $(\mathrm{t}=-6.774, \mathrm{p}<.001)$, 시행 전 자기개방 3.11점, 시행 후 자기개방 4.61점 $(\mathrm{t}=-$ $6.774, \mathrm{p}<.001)$ 로 증가하여 모두 통계적으로 유의한 차이를 나타내었다<Table 3>.

[표 3] 마음챙김 기반 중학생 인성교육프로그램 사전 사후 비교

[Table 3] Comparison of Effect of Mindfulness-based Personality Program Step 1 'Me(Understand Oneself)'

\begin{tabular}{|c|c|c|c|c|c|c|}
\hline \multirow{2}{*}{ Variables } & \multicolumn{2}{|c|}{ Pre } & \multicolumn{2}{c|}{ Pos } & \multirow{2}{*}{$\mathrm{t}$} & $p$ \\
\cline { 2 - 7 } & \multicolumn{2}{|c|}{ Mean \pm SD } & \multicolumn{2}{c|}{ Mean \pm SD } & & \\
\hline self-Esteem, & 3.26 & .59 & 4.43 & .61 & -8.847 & .000 \\
\hline Self-Understanding & 3.39 & 1.18 & 4.71 & .51 & -6.774 & .000 \\
\hline Self-Disclosure & 3.11 & .68 & 4.61 & .57 & -10.025 & .000 \\
\hline
\end{tabular}

\section{4. 결론}

본 연구는 심리적 과도기에 있는 청소년이 자신의 잠재능력을 개발하고 성장할 기회를 제공하며, 정서적 불안정성과 자아 혼란감을 극복하고 '진정한 나'를 확립하는 기초가 되 기 위한 마음챙김 기반 중학생 인성교육프로그램 1단계 '나(자신의 이해)' 시행 전과 시 행 후 자아존중감, 자기이해 및 자기개방에 영향을 미치는 효과를 알아보기 위하여 시도 되었다. 
본 프로그램은 자신의 이해를 통하여 타인과 새로운 관계 경험을 통해 정서적 심리적 어려움을 긍정적 에너지로 전환하도록 돕는 기회를 제공하기 위하여 4회기에 해당하는 프로그램으로 중학생에 적합한 학습 내용으로 구성하고 전문가의 자문 후 중학생 시기의 청소년에게 1단계‘나(자신의 이해)' 프로그램을 진행하였다.

본 프로그램은 처음 프로그램 도입시기에 자신의 감정을 감정 카드를 통하여 표현하도 록 하였으며 몸과 마음의 이완 및 주의 집중을 위한 명상을 통하여 자신에 대한 주의 집 중과 걷기 명상과 먹기 명상을 실시하여 기존의 참선과 같은 명상 요법 외의 방법과 감 정 향수 만들기를 활용하여 자아존중감과 자신을 이해하도록 하였다. 선행연구인 마음챙 김명상 프로그램에 참여한 대상자의 자아존중감에 관한 연구에서도 참여하지 않은 대상 자보다 향상되었다고 하였으며[15], 알아차림 명상을 통한 자기이해가 강화되었다고 하여 [19] 본 연구에서의 결과와 유사한 결과를 나타내었다.

본 프로그램 시행 전보다 시행 후 자아존중감, 자기이해 및 자기개방에서 긍정적인 결 과가 나타났는데 선행연구인 청소년의 자아존중감 및 자기표현 향상을 위한 Literacy Through Photography에서도 자신을 표현하게 되면서 자신감이 향상되어[8] 본 연구의 결과 와 유사한 결과를 나타내었다.

각 주차 별 주제에 따라 나의 뿌리 그리기, 장점 찾기 등을 통하여 자기이해와 자아존 중감을 증진시킬 수 있도록 학습 내용을 구성하고 마음블럭을 활용하여 다양한 모양을 통하여 표현하며 마무리 주차에 감정 향수 만들기 학습활동을 참여하여 자아존중감, 자 기이해 및 자기개방에 대하여 사후 점수가 증가하였다고 보인다. 연구 결과를 통하여 마 음챙김 기반 중학생 인성교육프로그램을 지속적으로 시행하여 청소년의 자아존중감과 자 기이해 및 자기 개방에 긍정적인 향상을 도모할 수 있는 인성교육프로그램으로 확장시키 고자 한다.

\section{5. 감사의 글}

This paper was supported(in part) by Research Funds of Kwangju Women's University in KWUI21052

\section{References}

[1] Korean Children and Youth Panel Survey 2010 IV, Korea Youth Policy Institute, (2013)

[2] Development of Standardized Personality Test for Elementary and Middle School Students, Korea Educational Development Institute, (2014)

[3] Kyung-sook Choi, Ha-na Song, Developmental Psychology, Gyeonggi-do: Gyomunsa, (2010)

[4] Growth and Development of Normal Adolescents, Ministry of Health and Welfare, (2013)

[5] S. Harter, Developmental perspectives on the selfsystem, (From the journal: Handbook of Child Psychology), New York: Wiley, (1983)

[6] Min-Kyung Kim, Ju-Duck Kim, Effect of appearance management behaviors and appearance satisfaction on selfesteem in teenagers, Asia Life Sciences, (2018), Vol.3, No.1, pp.7-12.

[7] Hyo-sun Kim, Development of a Self-esteem and Interpersonal Relationship Enhancement Program for Adolescents, Hannam University Graduate School of Education Theological Seminary, Master's Thesis, (2012) 
[8] Soo-Yeon Kim, A Study on a Photo Education Program for Improving Self-esteem and Self-expression of the Youth: A Case of LTP, Kookmin University Graduate School of Education, Master's Thesis, (2014)

[9] EunMi Kim, Hye Young Ahn, Jin Ju Woo, The Relationship between Emotional Maltreatment, Internalizing Problem Behavior, Self-Esteem, Social Support of Adolescents, International Journal of IT-based Public Health Management, (2018), Vol.5, No.2, pp.1-6, DOI: 10.21742/IJIPHM.2018.5.2.01

[10] Mika Lim, Jinsoo Kim, The Learning Styles of Middle School Student for Solving Technological Problems, AsiaPacific Journal of Educational Management Research, (2019), Vol.4, No.3, pp.21-28.

[11] Miran Bang, Sunsook Sim, The Effects of Daily Stress on Health Behavior of Adolescents- The Mediating Effects of Resilience, International Journal of IT-based Public Health Management, (2018), Vol.5, No.1, pp.7-12.

[12] Baek Hyun-ki, Kang Kyung-sook, Noh Jeong-eun, The Efect of Affirmation Psychology Program Based on Mindfulness on Psychological Well-Being of Adolescents, The Journal of Learner-Centered Curriculum and Instruction, (2017), Vol.17, No.3, pp.353-375, DOI: 10.22251/jlcci.2017.17.3.353

[13] S. G. Hofmann, A. T. Sawyer, A. A. Witt, D. Oh, The Effect of Mindfulness-based Therapy on Anxiety and Depression: A Meta-analytic Review, Journal of Consulting and Clinical Psychology, (2010), Vol.78, No.2, pp.169-183, DOI: $10.1037 / \mathrm{a} 0018555$

[14] K. E. Kim, J. S. Kim, The Meta-Analysis on the Effect of Mindfulness Programs, The Korea Journal of Youth Counseling, (2015), Vol.23, No.2, pp.135-155, DOI: 10.35151/kyci.2015.23.2.007

[15] Bong-goo Kim, The Effects of Mindfulness Meditation on Self-Esteem, Self-Efficacy, Ego-Resiliency and SelfRegulation of Adolescents, Hanyang Cyber University Graduate School of Human Services, Master's Thesis, (2016)

[16] Bo-Ga Choi, Gwiyeon Jeon, A Study on the Development of the Self - Esteem Inventory, Journal of the Korean Home Economics Association, (1993), Vol.31, No.2, pp.41-54.

[17] Ji-Hae Kim, Chang-Yil Ahn, Effect of Self-focused Attention on Anxiety, Korean Journal of Clinical Psychology, (1991), Vol.10, No.1, pp.243-261.

[18] Jin-Jeong Gyu, Hwa-Seong hwang, The Effects of Group Training Experience on Self-Awareness and Self-Disclosure of High School Students, Education Essay, (1996), Vol.27, pp.9-30.

[19] Yeo-Jeong Jeon, A Suggestion on the New Approach to Mindful Meditation as an Effective Therapy; Focused on its Mechanisms, Studies of Seon Culture, (2013), No.15, pp.221-254, UCI: G704-SER000001486.2013..15.007 